\title{
Problematic of the Assessment Activity within Adaptive E-Learning Systems
}

\author{
https://doi.org/10.3991/ijet.v14i17.10675 \\ Najoua Hrich ${ }^{(凶)}$, Mohamed Lazaar, Mohamed Khaldi \\ Abdelmalek Essaâdi University, Tetouan, Morocco \\ amine.najoua@gmail.com
}

\begin{abstract}
The purpose of this paper is to focus on the activity of assessment that takes a decisive place in the learning process and discuss the importance of this action for each participant of the process. After that, authors profile the desirable characteristics of an adaptive system and describe the importance of the assessment activity, the extent of its impact on the cognitive decision-making and the adaptation of learning within such systems. Later they present a model of e-assessment for an educational adaptive system, that can accept objects developed under open standards, by exploiting technology in the benefit of the pedagogy.
\end{abstract}

Keywords-Assessment, adaptive e-learning systems, competencies, ontologies, IMS- QTI

\section{Introduction}

The assessment is one of the most important components of the learning process as illustrated by the definition: "Assessment is a broad term that includes a comprehensive set of procedures used to obtain information about learner learning and make a value judgment about his progression" [1]

Despite this determining role of assessment, it should be noted that, in the majority of E-learning systems, the functionalities associated with the online assessment of learning are too limited.

Currently, several kinds of research on e-learning domain trend toward the personalization and the adaptation of the learning according to different approaches that make learner in the center of the learning process by taking into account its preferences, objectives, learning styles, knowledge level, ...etc. Among the inherent importance of these works, authors want to give emphasis on the assessment activity within the e-learning process. They want to focus their selves in this action and see how it can help to improve the learning process for all the participants: learners, teachers, content designers, etc. 


\section{Pedagogical Foundations}

Assessment is the process of judging learning from collected, analyzed and interpreted data for pedagogical and administrative decisions.

By wondering about its purposes, Jean CARDINET defines four, fundamentals: «

- Improve the learning's decisions for each learner.

- Inform learner and his parents about his progression

- Grant certificates to learners and to society

- Improve the quality of learning in general. » [2][3]

He specifies also that it's not possible to assess in the same way in all cases;

The assessment consists essentially of providing information in order to make decisions: propose learning activities, for supporting and remediation; grant a diploma and certificates of mastering competencies; Transform the modalities and strategies of teaching; etc.

By retaining the definition proposed by G.de LANDSHEERE: «Estimation by a grade a modality or a criterion considered in behavior or in production. », authors are led to valid the acceptance of the most trivial signification of the term which structures the most shared representation of its nature, and also the most reductive: assess, is mainly giving an average. This definition agrees with the third aim of assessment defined by J. CARDINET, but it is not relevant for the others.

G.de LANDSHEERE specifies that the assessment «.... includes both the qualitative and the quantitative description of behaviors and Contain, furthermore, a value judgment concerning their desirability. » [1]

\subsection{Diagnostic, formative and summative assessment}

Generally, there are three types of assessment: diagnostic, formative and summative assessment. authors suppose in their context that the diagnostic and formative assessment have the same objectives in order to improve the level of the learner.

Formative and diagnostic assessment: "It's an assessment which intervenes at the end of each learning task to inform learner and teacher about the level of knowledge and to discover where and in what learner has difficulties, in order to propose or to help him to discover new strategies that allow him to progress" G. Landsheere. [4]

It's an assessment mode which the main objective is the regulation of the learning process. Providing to the learner information about his progress relative to a defined objective, it allows to intervene during the learning process, to change learning content, allowing to the learner to differ his learning methods and strategies and then to decide of necessary help actions.

It's a way of assessment which consists to provide information, appreciation of work, learner's activities and productions: things that cannot be reduced on an encrypted result as a note or an average. Formative assessment is not, in all cases, a terminal assessment that comes after a task, it consists also a diagnostic assessment 
which comes at the beginning of learning sequence. It also can be a diagnostic assessment because it allows highlighting the learning difficulties and gives indicators about the encountered obstacles. In this way, it serves to implement activities to remove these learning obstacles. As it's mentioned by J. Cardinet. [2][3]

Summative assessment: The main objective of the summative assessment is an objective of certification; it allows to provide a review to situate learner relative to a standard or an established criterion and to make a decision: graduation

\subsection{Criterion and normative assessment}

There are two modalities of assessment:

- Normative assessment: Which compare the learners with each other.

- Criterion assessment: That allows to certificate what learners are able to do or not, independently of each other, by relating this certification to a set of predefined criteria. [5]

The normative assessment allows "To place the individual with regard to (compared with) a standard, constituted by the performances of a reference group." [4][5]

Criterion assessment verifies learners' performances based on a set of resources constituted on criterions relative to a defined model.

R. Glaser specifies "As the criterion tests are specially designed to supply information (directly interpretable) about performance's levels, these levels should be defined before building a test. The aim of testing is to evaluate the place of each individual regards to his levels." [5][6]

The adoption of criterion assessment allows the specification of the strengths, the weaknesses of each learner and consequently a relevant adaptation.

\subsection{Validation of a criterion: $2 / 3$ rule}

To certify that a learner has mastered a criterion, it is not enough to note, for once, that his production is relevant to the task in question. More seriously, it is not enough to note, for once, that production is not relevant to certify that the learner is incapable of producing a relevant production. This would be an excessive danger generalization, especially since the learner's error may be simply linked to a bad formulation of the instruction, to a temporary distraction, etc. [7]

Face to this difficulty, DE KETELE and ROEGIERS proposed to apply the " $2 / 3$ rule". The aim is to give the learner at least three independent opportunities to demonstrate his competency and thus to check each criterion. A learner masters a criterion when he succeeds at least twice out of the three opportunities offered to him and these opportunities must be truly distinct and independent of each other. [8] [9]

To offer an efficient diagnostic with relevant outcomes, authors adopt the $2 / 3$ rule for the verification of each concept in their proposed tool (section 4). 


\section{E-learning Systems: Adaptation}

The purpose of this section is to profile the desirable characteristics of an adaptive system and describe the importance of the assessment activity and the extent of its impact on the cognitive decision-making and on the adaptation of learning in such systems.

\subsection{Necessary model for adaptation}

In adaptive e-learning environments, the adaptation is based on well-organized models and processes. Different types of adaptive systems are based on the three main models [10]:

- A domain model

- A user model

- An adaptive model.

Domain model: Presents a structure of knowledge domain which is often referred to as a graph. Several researchers intend to build the domain model by using ontologies.

Adaptation model: Is the main component that gives effect to adaptation. It contains content and concepts selection rules. By applying these rules in content selection, it helps to choose the appropriate educational resources from the internal model. On the other hand, the concept selection rules are used to select the appropriate notions of the domain model. These rules must comply with a user model so that the selection becomes correct.

Learner model: Contains information and data about the learner.

\subsection{Adaptation facets}

Adaptive e-learning systems (AES) inspect learners 'characteristics and make appropriate adjustments to support learning. Their main goal is to flexible environment that supports learning for students with a range of abilities, disabilities, interests, backgrounds, and other characteristics. The challenge of accomplishing this goal depends largely on accurately identifying characteristics of a particular learner or group of learners - such as type and level of knowledge, skills, personality traits, affective states - and then determining how to leverage the information to improve student learning.

In AES, the form of a user knowledge model is the scalar model, which estimates the level of user domain knowledge by a single value on some scale - quantitative (a number ranging from 0 to 5 ) or qualitative (good, average, poor, none). Scalar models, especially qualitative, are quite similar to stereotype models. The difference is that scalar knowledge models focus exclusively on user knowledge and are typically produced by user self-assessment. Despite their simplicity, scalar models can be used effectively to support simple adaptation techniques. These systems divide their users 
into two or three classes according to their knowledge level of the subject (i.e., expert, intermediate, and novice) and serve different versions of the whole page content or page fragments to learners with different levels of knowledge. [11]

\subsection{Assessment process within the e-learning platforms}

IMS - Question \& Test Interoperability: E-learning systems must be flexible and efficient, the way to accomplish that is to be an open and standardized system. In the context of interoperability, the IMS Question \& Test Interoperability (QTI) specification describes a data model for the representation of question (assessmentItem) and test (assessmentTest) data and their corresponding results reports. Therefore, the specification enables the exchange of this item, test and results from data between authoring tools, item banks, test constructional tools, learning platforms, and assessment delivery systems.[12]

The specification provides for several types of questions: true/false question, multiple answer MCQ, text with holes, image map, move objects, the open question. Answers to questions can be simple, multiple or ordered. The specification allows controlling the objects by ordering and selecting them and integrates algorithms for calculating the scores.

Study of some e-learning platforms (opensource): Open source Learning Management Systems (LMS) were developed either by developer communities (Moodle), or by non-profit associations (Chamilo, Claroline Connect, Ilias), or by structures linked to universities or schools (Open Olat), or by companies (Dokeos, Canvas).

The following table presents some usual LMS with the possibility of implementing assessment activities:

Table 1. LMS with the possibility to implement assessment activities: questions format and components of feedback

\begin{tabular}{|c|c|c|c|c|}
\hline LMS & Description & IMS-QTi & Questions Format & Feedbacks \\
\hline $\begin{array}{l}\text { MOODLE } \\
\text { https://moodle.org/ }\end{array}$ & $\begin{array}{l}\text { Moodle is a free and open- } \\
\text { source LMS developed } \\
\text { on pedagogical principles, } \\
\text { Moodle is used for several e- } \\
\text { learning projects in schools, } \\
\text { universities, workplaces, and } \\
\text { other sectors. }\end{array}$ & $\begin{array}{l}\text { supports } \\
\text { adaptive } \\
\text { questions; } \\
\text { QTI }\end{array}$ & $\begin{array}{l}\text { short answer, numerical } \\
\text { question, multiple } \\
\text { choice, matching, de- } \\
\text { scription, random ques- } \\
\text { tion, short answer ran- } \\
\text { dom question, answers } \\
\text { included }\end{array}$ & $\begin{array}{l}\text { Scores, } \\
\text { Activities } \\
\text { Reports }\end{array}$ \\
\hline $\begin{array}{l}\text { SAKAI } \\
\text { https://www.sakailms.org/ }\end{array}$ & $\begin{array}{l}\text { Sakai is an open source collab- } \\
\text { oration and learning environ- } \\
\text { ment. Sakai is part of } \\
\text { the Apereo Foundation suite of } \\
\text { open source tools for education. }\end{array}$ & $\begin{array}{l}\text { Supports } \\
\text { QTI }\end{array}$ & $\begin{array}{l}\text { Fill in the Blank, Multi- } \\
\text { ple Choice, Multiple } \\
\text { Correct Answer, Short } \\
\text { Essay, True False. }\end{array}$ & $\begin{array}{l}\text { Report of } \\
\text { scores }\end{array}$ \\
\hline $\begin{array}{l}\text { ILIAS } \\
\text { https://www.ilias.de/ }\end{array}$ & $\begin{array}{l}\text { ILIAS is in development since } \\
1998, \text { it is now supported by } 12 \\
\text { premium partners and more } \\
\text { than } 40 \text { institutional club } \\
\text { members. } \\
\text { There are thousands of active } \\
\text { ILIAS installations worldwide } \\
\text { with millions of users. }\end{array}$ & $\begin{array}{l}\text { IMS QTI } \\
\text { tests and } \\
\text { exams }\end{array}$ & $\begin{array}{l}\text { QCM / QCU location } \\
\text { questions Closed ques- } \\
\text { tions (free text, check the } \\
\text { box) Tasks for hot spot } \\
\text { arrangements (search for } \\
\text { images to click on) }\end{array}$ & $\begin{array}{l}\text { Average } \\
\text { Mark }\end{array}$ \\
\hline
\end{tabular}




\begin{tabular}{|l|l|l|l|l|}
\hline OPEN OLAT & $\begin{array}{l}\text { Open Olat is an open-source } \\
\text { web-based learning manage- } \\
\text { https://www.openolat.com/ } \\
\text { ment system for teaching, } \\
\text { education, assessment and } \\
\text { communication }\end{array}$ & $\begin{array}{l}\text { Integrated } \\
\text { IMS- QTI } \\
\text { editors }\end{array}$ & $\begin{array}{l}\text { Fill in the Blank, Multi- } \\
\text { ple Choice, Multiple } \\
\text { Correct Answer, Short } \\
\text { Essay, true False. }\end{array}$ & Scores \\
\hline DOKEOS & $\begin{array}{l}\text { Dokeos is an open-source } \\
\text { customizable training platform } \\
\text { for train, evaluate and certify } \\
\text { https://www.dokeos.com/ } \\
\text { the skills of employees or } \\
\text { learners. }\end{array}$ & STI & $\begin{array}{l}\text { Fill in the Blank, Multi- } \\
\text { ple Choice, Multiple } \\
\text { Correct Answer, Short } \\
\text { Essay,True False. }\end{array}$ & Scores \\
\hline
\end{tabular}

Assessment Process: Conceptualizing the adaptive e-learning process to its basic elements, three elements could be identified [13]:

- The educational content to be taught

- The assessment activity to measure learner learning

- The score results obtained

The profile generated is based especially on the score results and the adaptation as well. Figure 1 presents those elements that describe the assessment process within an e-learning system.

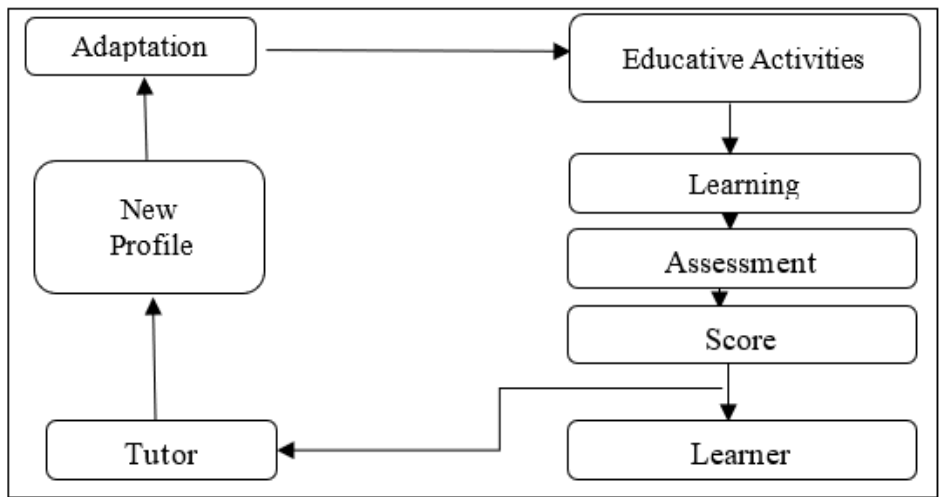

Fig. 1. Current process of E-assessment

The results of the assessment are translated by an affectation of a learner cognitive profile according to the score obtained. Learners who had the same score have the same cognitive profile and also the same remedial activities. In this case, learners who have the same score, even if they have different learning deficiencies, get the same remediation since the score brings the same information; and it is here where resides the whole problem of the adaptation in terms of the remedial activities' content.

Assessment, as cited in previous sections, has to improve the learning process, by providing an efficient diagnostic, to identify learning difficulties, in order to precise the real cognitive state. This latter is one of the several important factors to be considered by designers of adaptive e-learning systems. 


\subsection{Requirements and needs for e-assessment}

The e-assessment is an important step inside the e-learning process because gives convenient feedback to all participants in the process helps to improve the learning and teaching experience.

In AES, the assessment is often based on multiple choice questions (MCQs). Each assessment test sanctions the learner by a final score. The result represented within this score does not allow a reflection on the exact learner's cognitive state nor on the source of its gaps. In addition, the type of questions used in such system makes a place to randomness, trial, and error. On the other hand, several kinds of research illustrate the low consideration of the assessment by the e-learning platforms and their infrastructures. The primary objective of scriptwriting is above all to script the educational activities, and that the question of evaluation is not central to it. It is certainly treated but partially and unsatisfactory in terms of practices.

In addition, the questions used to cover the whole of a module, a unit, a chapter or a lesson according to the object of the assessment. Thus, the assessment must find its place in the scripting of educational activities. Scripting allows the teacher to build the activities he desires and enable him to implement the assessments he wants to conduct.

\section{Proposal Tool for Assessment}

To present an efficient diagnostic, authors have conceived in previous works an assessment ontology that allows to assess each component of a competency. To valid the acquisition of a concept, the $2 / 3$ rule, cited above, is adopted and if there is a difficulty the proposed approach is more relevant and specifies exactly where lies the problems. [14]

With those characteristics, our proposal allows to improve the learning process in different ways:

For the student: Being exposed to a content that suits his profile and that targets the knowledge he lacks, by using an optimal pedagogical approach that keeps the learner in his proximal development zone (PDZ), he is more likely to perceive his learning as relevant and challenged and he focuses on notions he does not master and he devotes all his energy to the learning he needs.

For the tutor/teacher: The tool provides precious information that allows him to identify what knowledge and skills he would develop with his learners. Thanks to the collected data, this tool allows him to know if the invested efforts in training report as desired or it is necessary to adjust the shot.

The figure 2 presents a narrow conceptualization for a complex process in which there are other several factors that must be taken into account such a learning styles, technical implications, adaptive educative content, learning and knowledge management, motivation, etc. 


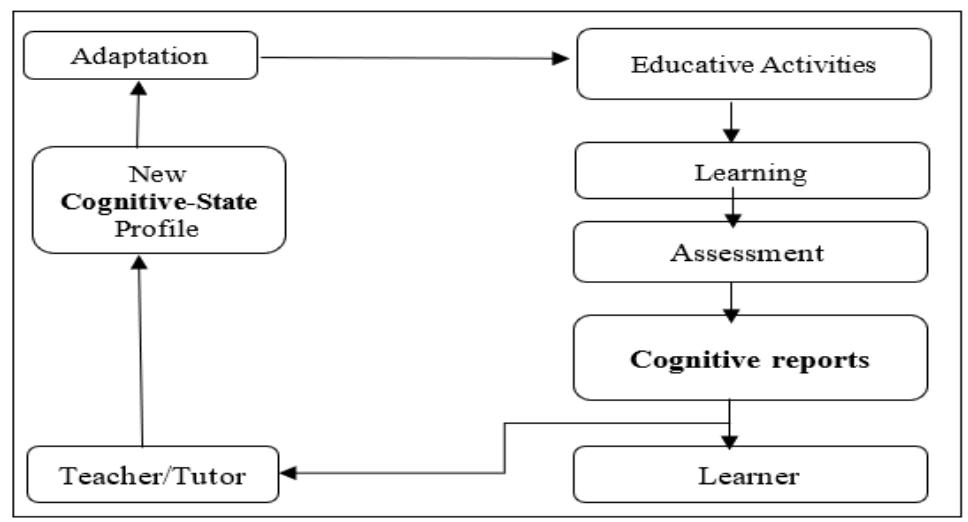

Fig. 2. Proposal process of assessment

Cognitive reports: Showed in figure 2 present feedbacks for learners and teachers. According to Hattie, Feedback refers to the process of securing information enabling change through adjustment or calibration of efforts in order to bring a person closer to a well-defined goal.[15]

In order to achieve the main goal of the assessment activity, the proposed tool presents two types of report which contain useful feedbacks for both teachers and learners: Learner Report and Teacher Report

\section{Learner report}

- The acquired $\&$ the non-acquired concepts

- The capacity of their mobilization to apprehend a situation and to resolve it.

- Other alternatives to solve the task

- An indication of tracks of deepening / prolongation.

Teacher/Tutor report: When learners make erroneous reasoning, the teacher can ask/assess if the strategies he used at his teaching sessions are optimal or not; and what he has to change for remediation.

- The rate of learners who acquired / not acquired each concept

- The rate of learners who are able to mobilize concepts for resolving complex situations

- List of concepts which need remediation

\section{$5 \quad$ Conclusion and Further Work}

The E-assessment is an important step inside the e-learning process because gives convenient feedback to all participants in the process helps to improve the learning and teaching experience.

In this paper, authors wanted to emphasize the role of the assessment by putting it at the center of the e-learning process and defining the important factors that partici- 
pate in this process: the specification of learner's source of errors and overcome them in real time is the key of any adaptation.

The adaptation must first take into account the content of the activity to present for the learner and then the way it will be presented (according to his learning style); In this article, authors present a novel view of assessment which could be exploited into adaptive e-learning systems. The proposed approach allows to specify for each learner the adapted content and then the way to present it according to their preferences and their learning styles.

\section{References}

[1] Robert, L. Linn., \& Gronlund, Norman E. (1995). Measurement and assessment in teaching (7th ed.). Englewood Cliffs, NJ: Prentice Hall.

[2] Cardinet, J. (1986 a). Pour apprécier le travail des élèves. De Boeck,

[3] Cardinet, J. (1986 b). Évaluation scolaire et pratique, Bruxelles. De Boeck 1988, p. 133.

[4] De LANDSHEERE, G. (1992). Dictionnaire de l'évaluation et de la recherche en éducation. Presses Universitaires de France: 2ème édition revue et augmentée.

[5] Landsheere, V. d. (1988). Faire réussir, faire échouer; La compétence minimale et son évaluation. Paris: Presses Universitaires de France.

[6] Bourgoz Froidevaux, A. (2017). Les écrits de Jean Cardinet. Citations commentées. Evaluer. . Journal international de Recherche en Education et Formation, 3(3), 97-104.

[7] Astolfi, J.-P. (2011). l'erreus outil pour enseigner. ESF éditeur.

[8] DE KETELE, J.-M. (1996). L'évaluation des acquis scolaires : quoi ? pourquoi ? pour quoi ? Revue Tunisienne des Sciences de l'Éducation, 23, 17-36.

[9] Roegiers, X. (2005). L'évaluation selon la pédagogie de l'intégration.

[10] Snow, R. E. (1994). Abilities in academic tasks. In R. J. Sternberg \& R. K. Wagner (Eds.), Mind in context: Interactionist perspectives on human intelligence, 3-37.

[11] Hrich, N., Lazaar, M. \& Khaldi, M. (2017). A model for pedagogical supporting based on competencies evaluation and ontologies. International Research Journal of Computer Science (IRJCS), 43-49.

[12] IMS QTI. (2015). IMS Question and Test Interoperability (QTI): Overview Version 2.2. Retrieved from http://www.imsglobal.org/question/qtiv2p2/imsqti v2p2 oview.html

[13] Héctor Barbosa. \& Francisco Garcia. (2005). Importance of Online Assessment in the Elearning Process. In Proceedings of the 6th International Conference on Information Technology Based Higher Education and Training (ITHET 2005),1-6. https://doi.org/10.1109/ ithet.2005.1560287

[14] Hrich, N., Lazaar, M. \& Khaldi, M. (2019). Improving Cognitive Decision-Making into Adaptive Educational Systems through A Diagnosis Tool based on competency approach. international journal Emerging Technologies in Learning (i-jet), 14(7), 226-235. https://doi.org/10.3991/ijet.v14i07.9870

[15] Hattie \& Yates. (2014). Visible learning and the science of how we learn. Routledge, NY, 66. 


\section{$7 \quad$ Authors}

Najoua Hrich is with Computer lab, operational research, and applied statistics, Abdelmalek Essaadi University, Faculty of Sciences, Tetouan, Morocco (e-mail: amine.najoua@gmail.com).

Mohamed Lazaar is with Computer lab, operational research, and applied statistics, Abdelmalek Essaadi University, National School of Applied Sciences (ENSA), Tetouan, Morocco (e-mail: lazaar@gmail.com).

Mohamed Khaldi is with Computer lab, operational research, and applied statistics, Abdelmalek Essaadi University, Faculty of Sciences, Tetouan, Morocco (e-mail: medkhaldi@yahoo.fr).

Article submitted 2019-04-16. Resubmitted 2019-06-07. Final acceptance 2019-06-08. Final version published as submitted by the authors. 